\title{
Catecholamines and free fatty acids in myocardial infarction and angina
}

\author{
SUBHASH C. SHARMA \\ From the Army Hospital, Delhi Cantt-110010, India
}

SUMMARY Total urinary catecholamines and plasma free fatty acids (FFA) were estimated serially in 50 patients with myocardial infarction (A) and in 27 cases of angina (B). A group of 24 normal healthy subjects $(C)$ were also studied as controls. Catecholamines were significantly high $(P<0.001)$ in group $\mathrm{A}$ in the first 48 hours after infarction as compared to group C. Group B did not show significant variation from the normals (C). FFA also tended to increase only in group $A$ in the first 48 hours. Both the parameters had returned to normal by 72 hours. The significance of the findings is discussed.

Considerable interest has been shown lately in the role of catecholamines and free fatty acids (FFA) in ischaemic heart disease. These have been characterised as important prognostic indicators of the severity of myocardial damage (Oliver et al., 1968; Januszewicz et al., 1968; Hayashi et al., 1969; McDonald et al., 1969; Taylor et al., 1969; Rutenberg et al., 1969). These biochemical measurements probably reflect generalised metabolic response to the stress of ischaemia. Cases of myocardial infarction and ischaemia without infarction (angina) differ primarily in the extent and degree of damage to the heart. The pathogenesis in both these clinical entities is apparently the same. The possible significance of catecholamines in the development of angina has been reviewed by Black and Prichard (1973). It is widely assumed that angina follows an imbalance in the oxygen supply and demand. Catecholamines increase demand by raising heart rate and force of contraction of the heart and by stimulating cardiac metabolism, commonly referred to as an oxygenwasting effect (Sarnoff et al., 1965). For example, the effect of raised FFA levels after isoprenaline infusion is to raise myocardial oxygen consumption significantly more than the effect of heart work alone (Mjøs, 1971).

Accordingly, we estimated total urinary catecholamine excretion and plasma FFA in cases of acute myocardial infarction and angina. A group of normal, healthy, age-matched subjects were also studied for comparison. The results are reported.

Received for publication 4 May 1977

\section{Material and methods}

One hundred and one subjects were studied in the following groups.

\section{GROUP A}

Fifty patients with acute myocardial infarction (AMI), 31-73 years of age, admitted to the intensive coronary care unit of this hospital formed this group. Diagnosis was based upon the typical history, electrocardiographic findings, and enzyme estimations (Lawrie et al., 1967). Cases with diabetes mellitus, hypertension or any endocrine disorder were excluded from the study.

\section{GROUP B}

Twenty-seven patients aged 26-85 years were admitted to this hospital with acute chest pain and a typical clinical history of myocardial ischaemia but electrocardiographic studies and enzyme estimations did not confirm the presence of infarction (angina).

\section{GROUP C}

A group of 24 healthy individuals aged 25-79 years with no clinical or laboratory evidence of heart disease or endocrine disorder acted as normal controls.

A fasting blood sample was collected from the antecubital vein immediately after admission (day 1 ) and then on the morning of days 2, 3, and 14 in hospital. Free fatty acids (FFA) were estimated by the method of Trout et al. (1960).

Twenty-four-hour urine samples were collected 
for estimation of urinary catecholamines on days 1,2 and 3 in hospital. Each subject was given a marked container in which to void urine. Hydrochloric acid and ascorbic acid were used as preservatives. Total urinary catecholamines (free noradrenaline plus adrenaline) excretion was estimated by the trihydroxyindole method of Anton and Sayre (1962).

\section{Results}

The mean ages of the subjects were $56 \cdot 6,54 \cdot 9$, and 50.3 years in groups $A, B$, and $C$ respectively. The values and results of statistical analysis are given in the Table. Group A showed a significant increase in catecholamine excretion on the day of the acute episode as compared to groups B and C. The excretion rate gradually decreased thereafter.

Catecholamines in group A were still high ( $P<$ 0.001 ) on the second day as compared to group $C$ and reached near normal levels by the third day. Group B, on the other hand, showed no significant difference from group $\mathrm{C}$ during the first three days of the acute episode. FFA in group A also showed a rising trend. Values were maximum on day 1. Patients with AMI (group A) showed significantly high FFA on the first two days as compared to groups B and C. No such rise was observed in group B patients.

\section{Discussion}

The increased excretion of catecholamines is probably part of the stress reaction associated with infarction and its complications, the source being adrenal glands and sympathetic nerve endings. Stimulation of these may occur reflexly from stretch sensors in the left atrium, or from various chemoreceptors and/or skin temperature sensors (Lancet, 1969; Rosenbaum and Doyle, 1970). The FFA are increased by the catecholamines and may be deposited as triglycerides in the heart or utilised for intracellular respiration via the citric acid cycle.

The present study reveals an increase in catecholamine excretion during the first 48 hours of infarction as compared to the normals. No such rise was noted in patients with angina. von Euler and Hellner (1952) postulated that the increased urinary excretion of catecholamines points to heightened sympathoadrenal activity, such as occurs in conditions of stress. This, however, depends on the renal flow. In a previous study, for example, patients with uncomplicated infarcts had higher urinary catecholamines than the patients with complications, since the latter group had a decreased renal flow (Klein et al., 1968; Januszewicz et al., 1968). Hayashi et al. (1969) reported increased urinary catecholamine output in the first 48-72 hours after infarction and are in agreement with our results. Experimental studies in dogs have revealed that the infarcted myocardium loses its catecholamines within the first 24 hours (Hayashi et al., 1969). In addition, Gertler et al. (1970) reported that the depletion of catecholamines from human papillary muscle correlated with the degree of failure. We did not find any significant increase in catecholamine excretion in cases of angina (group B) although they were alse under appreciable stress associated with pain and worry. Our findings accord with those of Rosenbauns and Doyle (1970), who also reported that catechol:amine excretion was unchanged in patients who suffered chest pain without infarction.

The rise noted in FFA in our patients with infarction was not very high. A rising trend in general tended to follow the catecholamine excretion pattern. The level of FFA not only reflects the increased levels of catecholamines but may also adversely affect the clinical course (Oliver et al., 1968). It has been shown that FFA depress hypoxic myocardium (Henderson et al., 1970) and may also be associated with serious chemical arrhythmias, although they

Table Total urinary catecholamine excretion $(\mu g / 24 h)$ and plasma free fatty acids $(\mu \mathrm{Eq} / \mathrm{l})$ in acute myocardial infarction $(A)$, angina $(B)$, and normals $(C)$. Values are means $\pm S E M .1,2,3$, and 14 denote the days after the acute episode. $N S=$ not significant.

\begin{tabular}{|c|c|c|c|c|c|c|c|c|c|}
\hline \multirow[t]{2}{*}{ Group } & \multirow{2}{*}{$\begin{array}{l}\text { Age } \\
(y r)\end{array}$} & & \multicolumn{3}{|c|}{ Urinary catecholamines } & \multicolumn{4}{|c|}{ Free fatty acids } \\
\hline & & & 1 & 2 & 3 & 1 & 2 & 3 & 14 \\
\hline $\begin{array}{l}\text { A } \\
\text { B } \\
\text { C }\end{array}$ & $\begin{array}{l}56 \cdot 6 \\
54 \cdot 9 \\
50 \cdot 3\end{array}$ & & $\begin{array}{l}83.4 \\
\pm 11.8 \\
55.9 \\
\pm 8.6\end{array}$ & $\begin{array}{c}74 \cdot 3 \\
\pm 9 \cdot 1 \\
62 \cdot 2 \\
\pm 12 \cdot 6 \\
46 \cdot 1 \pm 4 \cdot 2\end{array}$ & $\begin{array}{l}52 \cdot 0 \\
\pm 9 \cdot 0 \\
52 \cdot 9 \\
\pm 7 \cdot 1\end{array}$ & $\begin{array}{l}435 \cdot 1 \\
\pm 32 \cdot 2 \\
365 \cdot 9 \\
\pm 31 \cdot 9\end{array}$ & $\begin{array}{l}395 \cdot 2 \\
\pm 23 \cdot 2 \\
324 \cdot 2 \\
\pm 20 \cdot 1 \\
\quad 325\end{array}$ & $\begin{array}{l}351 \\
\pm 17 \cdot 7 \\
323 \cdot 5 \\
\pm 18 \cdot 1\end{array}$ & $\begin{array}{l}335.6 \\
\pm 11.4 \\
314.0 \\
\pm 20.7\end{array}$ \\
\hline $\begin{array}{r}\text { P-value } \\
\mathrm{A} v \mathrm{~B} \\
\mathrm{~A} v \mathrm{C} \\
\mathrm{B} v \mathrm{C}\end{array}$ & & $\begin{array}{l}< \\
<\end{array}$ & $\begin{array}{l}0.05 \\
0.001 \\
\text { NS }\end{array}$ & $\begin{aligned} & \text { NS } \\
< & 0.001 \\
& \text { NS }\end{aligned}$ & $\begin{array}{l}\text { NS } \\
\text { NS } \\
\text { NS }\end{array}$ & $\begin{array}{l}<0.05 \\
<0.001 \\
\text { NS }\end{array}$ & $\begin{array}{l}<0.01 \\
<0.05 \\
\text { NS }\end{array}$ & $\begin{array}{l}\text { NS } \\
\text { NS } \\
\text { NS }\end{array}$ & $\begin{array}{l}\text { NS } \\
\text { NS } \\
\text { NS }\end{array}$ \\
\hline
\end{tabular}


may not be responsible for them (Rutenberg et al., 1969; Nelson, 1970).

\section{References}

Anton, A. H., and Sayre, D. F. (1962). A study of the factors affecting the aluminum-oxide-trihydroxyindole procedure for the analysis of catecholamines. Journal of Pharmacology and Experimental Therapeutics, 138, 360-375.

Black, J. W., and Prichard, B. N. C. (1973). Activation and blockade of B-adrenoceptors in common cardiac disorders. British Medical Bulletin, 29, 163-167.

Gertler, M. M., Saluste, E., and Spencer, F. (1970). Biochemical analyses of human papillary muscles and guinea pig ventricles in failure. Proceedings of the Society for Experimental Biology and Medicine, 135, 817-824.

Hayashi, K. D., Moss, A. J., and Yu, P. N. (1969). Urinary catecholamine excretion in myocardial infarction. Circulation, 40, 473-481.

Henderson, A. H., Most, A. S., Parmley, W. W., Gorlin, R., and Sonnenblick, E. H. (1970). Depression of myocardial contractility in rats by free fatty acids during hypoxia. Circulation Research, 26, 439-449.

Januszewicz, W., Sznajderman, M., Wocial, B., and Preibisz, J. (1968). Urinary excretion of free norepinephrine and free epinephrine in patients with acute myocardial infarction in relation to its clinical course. American Heart Journal, 76, 345-352.

Klein, R. F., Troyer, W. G., Thompson, H. K., Bogdonoff, M. D., and Wallace, A. G. (1968). Catecholamine excretion in myocardial infarction. Archives of Internal Medicine, 122, 476-482.

Lancet (1969). Editorial. Catecholamines and myocardial infarction. Lancet, 2, 1051-1052.

Lawrie, D. M., Greenwood, T. W., Goddard, M.,Harvey, A. C., Donald, K. W., Julian, D. G., and Oliver, M. F.
(1967). A coronary-care unit in the routine management of acute myocardial infarction. Lancet, 2, 109-114.

McDonald, L., Baker, C., Bray, C., McDonald, A., and Restieaux, N. (1969). Plasma-catecholamines after cardiac infarction. Lancet, 2, 1021-1023.

Mjøs, O. D. (1971). Effect of inhibition of lipolysis on myocardial oxygen consumption in the presence of isoproterenol. Journal of Clinical Investigation, 50, 1869-1873.

Nelson, P. G. (1970). Free fatty acids and cardiac arrhythmias (Letter). Lancet, 1, 783.

Oliver, M. F., Kurien, V. A., and Greenwood, T. W. (1968). Relation between serum-free-fatty-acids and arrhythmias and death after acute myocardial infarction. Lancet, 1, 710-715.

Rosenbaum, M., and Doyle, A. E. (1970). Catecholamine excretion with myocardial ischaemia and infarction. Australasian Annals of Medicine, 4, 310-318.

Rutenberg, H. L., Pamintuan, J. C., and Soloff, L. A. (1969). Serum-free-fatty-acids and their relation to complications after acute myocardial infarction. Lancet, 2, 559-564.

Sarnoff, S. J., Gilmore, J. P., Weisfeldt, M. L., Daggett, W. M., and Mansfield, P. B. (1965). Influence of norepinephrine on myocardial oxygen consumption under controlled hemodynamic conditions. American Journal of Cardiology, 16, 217-226.

Taylor, S. H., Saxton, C., Majid, P. A., Dykes, J. R. W., Ghosh, P., and Stoker, J. B. (1969). Insulin secretion following myocardial infarction with particular respect to the pathogenesis of cardiogenic shock. Lancet, 2, 1373-1378.

Trout, D. L., Estes, E. H., Jr., and Friedberg, S. J. (1960). Titration of free fatty acids of plasma: a study of current methods and a new modification. Journal of Lipid Research, 1, 199-202.

von Euler, U. S., and Hellner, S. (1952). Excretion of noradrenaline and adrenaline in muscular work. Acta Physislogica Scandinavica, 26, 183-191. 